child psychiatry at registrar level after completing his Membership Examination, but his overall training must be in general psychiatry.

If we do have a specialist element in the examination, and this would be against my advice, it should be in a fourth year programme. In the main, my plea is: let us improve training, the examination and the examiners, and hope that this results in better candidates in the future.
REFERENCES

Harden, R. M. \& Gleeson, F. A. (1979) Assessment of clinical competence using an objective structured clinical examination (OSCE). Medical Education Booklet, No. 8 Association for the Study of Medical Education.

Hassall, C. \& Trethowan, W. H. (1978) Multiple choice examinations: Their predictive value in the Preliminiary Test and the Membership Examination. Bulletin, June, pp 101103.

\title{
Examination, Accreditation or Inspection?
}

\author{
By R. E. Kendell," Professor of Psychiatry, University of Edinburgh
}

What is the best way of maintaining and raising the quality of 'higher' (i.e. senior registrar) training, and the best way of ensuring that aspiring psychiatric specialists are competent to undertake the tasks ahead of them? Basically, three alternatives are available-examination, or 'accreditation' of individual trainees, or inspection of training postsand my purpose is to discuss the advantages and disadvantages of these alternatives.

\section{Examination}

All medical specialties in this country have an examination (for the Membership or Fellowship of the Royal College concerned) at some stage in postgraduate training. Some, like the physicians, have an 'entry exam' which has to be passed before the candidate can begin specialist training. Others, like the pathologists, have an 'exit exam', in which success marks the completion of specialist training. At present the examination for the Membership of our College comes at the half way stage, at the end of 'general' (i.e. registrar) training but before starting 'higher' training. An examination at the end of higher training could, therefore, either be a replacement for or an addition to this existing exam. Either, it seems to me, would have grave disadvantages. Although many of our sister colleges have a two-part examination, as we do, none requires its recruits to pass two separate examinations, and there is little doubt that an additional examination at the end of higher training would be extremely unpopular with trainees and might well inhibit recruitment to our discipline. Moreover, because, at our own request, the Health Departments recognise five distinct types of psychiatrist and provide separate career structures for each, there would have to be five separate examinations, or at least five different specialist subjects. The most serious disadvantage of an 'exit examination', however, is that it is simply not feasible to say to a trainee after six or more years of specialized training that he is not good enough and must move into some other branch of medicine. Consequently, either everyone must pass the examination, which converts it

- Although the author has been one of the College's representatives on the JCHPT since 1975 and chairman of the General Psychiatry SAC since 1978, the opinions expressed are his own. into a pointless ritual, or it must be possible for those who fail to remain in psychiatric practice. In the United States this is possible. Partly because the examining body (the American Board of Psychiatry and Neurology) is quite distinct from the professional association (the American Psychiatric Association), and partly because a large proportion of American psychiatrists are private practitioners who do not need appointments in government hospitals, many American psychiatrists thrive happily without passing their Boards. Provided they are 'Board eligible' (i.e. have completed a recognized residency training) they are professionally secure. In the United Kingdom, however, this would not be possible unless the NHS provided a second subconsultant career structure for those who could not pass the exam, and the College itself was prepared either to exclude part of the profession from its activities or to create a second less exalted breed of Member. Lastly, it is important to remember, as Professor Brandon points out in another article, that the present Membership examination has many shortcomings which no one has yet been able to eliminate, and that there is a widespread feeling that it should come earlier rather than later in training.

\section{Accreditation}

This is the technical term for the formal designation of a medical practitioner as a registered specialist on completion of an approved programme of training. Most Western countries have some such system, the responsible body being either the Ministry of Health, or other government department, or a professional association analogous to our Royal Colleges. In the EEC, for example, specialist registration is conferred after four years of approved specialist training and any British graduate wishing to practise in another EEC country can obtain an appropriate certificate from the GMC if he has passed the College Membership examination and completed at least one year of senior registrar training. In this country the (Todd) Royal Commission on Medical Education recommended in 1968 that there should be 'a system of vocational registration as the necessary complement to a proper system of professional training', and that the General Medical Council 'should be the vocational registration authority'. This view was endorsed in 1975 by 
the (Merrison) Committee of Inquiry into the Regulation of the Medical Profession: 'The GMC should control the standards of specialist medical education as it controls the standards of undergraduate medical education. We recommend that this control be brought about through the GMC maintaining a specialist register.'

There is certainly much to be said in favour of specialist registration. First and foremost, it provides the public with an important safeguard by ensuring that only those who are adequately qualified can describe themselves as cardiologists, neurosurgeons or child psychiatrists. It may also confer important advantages on the individual concerned, by entitling him to a higher salary or enabling him to charge higher fees. Thirdly, it enables the body responsible for the register to control, indeed to dictate, the length and content of postgraduate training both in government hospitals and in private practice. In most countries these advantages are decisive. In the United Kingdom, however, the NHS's unique system of consultant appointments and the existence of a powerful Joint Higher Training Committee (JHTC) in every specialty makes the situation much less clear cut.

In this country most doctors work within the Health Service, and the great majority of those who do engage in private practice also have Health Service appointments. In hospital or specialist practice only consultants exercise 'independent clinical authority', and there is an elaborate mechanism for ensuring that only those who are properly qualified become consultants. For example, all consultant posts have to be publicly advertised and the Royal College concerned and other bodies, such as universities, have representatives on the appointments committee. So for the most part the public is adequately protected already. Nor is accreditation of any obvious benefit to the doctor himself. The Health Departments have never offered to pay higher salaries to senior registrars on accreditation or to guarantee them consultant posts. Finally, and perhaps most important of all, the JHTCs have all the power they need to control the content of training programmes, whether or not they bestow accreditation on individuals on completion of training. This is because any senior registrar post which does not receive 'education approval' from the Joint Committee lapses as soon as its incumbent leaves, and cannot be refilled until education approval has been regained. In short, most of the advantages of specialist registration are already achieved by other means. It is, of course, true that at present there are no controls over psychiatrists in full-time private practice, but such people are very few in number. It is also true that inadequately trained people are sometimes appointed to consultant posts in shortage specialties such as geriatric medicine, radiology and mental subnormality (partly because college representatives on appointments committees fail to speak out). But experience has shown that accreditation does not prevent this. Consultant appointment committees are perfectly free to appoint non-accredited applicants if they wish to, and other JHTCs which do accredit give accreditation automatically to anyone who is appointed to a consultant post regardless of the adequacy of their previous training. It is clear, therefore, not only that accreditation and consultant appointment are alternative means of ensuring adequate standards of specialist practice but that where the two systems conflict it is the latter, consultant appointment, which takes priority.

There are, of course, situations in which it may be wise to wear both belt and braces. But before donning the braces of accreditation it is advisable to consider the hazards as well as the advantages of doing so, and in my view a system of accreditation would have serious disadvantages for our subject. It would be one more set of forms, one more hurdle for the trainee to surmount, one more fee to be paid, a further extension of medical bureaucracy. There would be no clear benefit to the individual concerned in terms either of salary or job security, and the Health Departments' ruling that all senior registrar posts must have education approval from the appropriate JHTC already gives that committee all the power it needs to influence the content of training programmes. But the most important disadvantage of requiring individual trainees to obtain accreditation at the end of their training is that it tends to impose the same training, the same sequence of professional experiences, on everyone, and so discourages all but the most self-confident and enterprising trainees from doing research, going abroad or pursuing unorthodox careers of any kind. It would even make it difficult for people to train partly in one specialty and partly in another, general psychiatry and mental subnormality for example. JHTCs all see themselves as 'raising standards' and emphasize how flexible they are, and they are sincere in this. But, whatever their intentions, they tend to impose an unnecessary and undesirable uniformity which can easily stifle initiative and hinder innovation.

At present able trainees are free to pursue unorthodox careers without worrying whether some distant, impersonal body will be prepared to accredit them at the end of the day. They do, of course, have to convince a consultant appointments committee or a similar university body that they are adequately trained for the post for which they are applying. But they can argue their case in person, and an appointments committee is much better placed to make an appropriate decision than any central accrediting body. It can interview candidates and obtain confidential reports from referees, and usually has access to other personal information as well. Moreover, it only has to decide whether the candidate is adequately trained for the particular post in question, and a training which might be inadequate for 'general psychiatry' as a generic discipline might well be ideal for a specialized post in, say, rehabilitation or alcoholism, or a senior lectureship in a university department.

The advantages and disadvantages of accreditation were debated at length by the Joint Committee on Higher 
Psychiatric Training two or three years ago, and also by the AUTP and the College Council. Eventually it was decided not to accredit individual senior registrars at the end of their training, despite the fact that most other JHTCs were already doing so, and this decision seems unlikely to be reversed in the near future. Opinion within the committee was fairly evenly divided. Representatives of the specialties, particularly child psychiatry and psychotherapy, tended to be in favour because they saw accreditation as a means of raising standards and promoting their own autonomy. The majority of general psychiatrists, on the other hand, took the opposite view, suspecting that accreditation would make training unnecessarily stereotyped and discourage research. They were also impressed by the magnitude of the administrative burden on the committee itself. Similar differences of opinion seem to have developed in the other JHTCs. Amongst the physicians, for example, most of the specialists (cardiologists, endocrinologists, neurologists etc.) were strongly in favour of accreditation, and general physicians and processors of medicine against. Indeed, both the Medical Research Council and the Committee of ViceChancellors and Principals have made formal complaintsor perhaps I should say have given formal expression to their anxieties-about the ill effects of accreditation on clinical research. The crucial difference between physicians and psychiatrists, of course, is that general psychiatrists are still in a majority, whereas general physicians are now heavily outnumbered. It may also be the case that at times basic clinical training in departments of medicine suffered because of an undue emphasis on research in a way that never had a chance to happen in psychiatry, and that this imbalance needed to be corrected.

\section{Inspection}

The third means of improving senior registrar training and the overall professional competence of psychiatrists generally is to inspect training posts, and for the last five years the Joint Committee on Higher Psychiatric Training

\section{Forthcoming Events}

The fifth annual S. H. Foulkes Leeture of the Group Analytic Society (London), 'Beyond the Unconscious: Group Analysis Applied', given by Mrs M. L. J. Abercrombie of the Clinical Medical School, Cambridge, will be held at the Royal College of Physicians, $11 \mathrm{St}$ Andrew's Place, London NWI on 18 May 1981 at $8.30 \mathrm{pm}$. Information: Group Analytic Society, 1 Bickenhall Mansions, London W1H 3LF.

On 15 May 1981 the Institute of Family Therapy is holding a workshop on 'Dying, Death and Mourning in Families'. Information: Course Secretary, Institute of Family Therapy, 5 Tavistock Place, London WC1. and its five subcommittees have devoted their energies, and the time of their members, to this end. Every senior registrar and honorary senior registrar post in the country has been inspected at least once during this period, and some two or even three times. It is an expensive and time-consuming business for all concerned, and senior registrars themselves are probably in a better position to judge how much good has been achieved than anyone else. Most members of the Joint Committee's inspection teams believe that their visits have been useful in a variety of ways: by making consultants, and senior registrars themselves, think constructively, sometimes for the first time, about the quality of the latter's training and how it might be improved; by spreading good ideas from one centre to another; sometimes by insisting that radical changes be made under threat of withdrawal of education approval; and occasionally by the actual withdrawal of approval.

I believe that this process of regular inspection of training posts by representatives of an authoritative national body, coupled with the existing mechanism of consultant appointment committees, is the best way of improving training and ensuring that the average standard of psychiatric practice is as high as possible. Other more elaborate systems might achieve more, but only, I think, at a much higher cost.

It may well be, of course, that in a year or two's time the General Medical Council will act on the advice of Todd and Merrison and introduce a specialist register akin to the existing Medical Register. If it did so it would almost certainly seek the assistance of the JHTCs, and under those circumstances I imagine the Joint Committee on Higher Psychiatric Training would agree without hesitation to accredit, and do its best to operate the system as flexibly as possible. But there is a world of difference between doing something pointless and unnecessary because one is obliged to and doing it on one's own initiative. It is also by no means a foregone conclusion that the GMC will decide to introduce specialist registration in view of the diplomatic and financial as well as the professional considerations involved.

The 5th World Congress of Sexology will take place in Jerusalem from 21 to 26 June 1981. Information: The Secretariat, 5th World Congress of Sexology, PO Box 29784, Tel Aviv, Israel.

The 11th International Congress for Suicide Prevention and Crisis Intervention will be held in Paris from 5 to 8 July 1981. Information: Dr J. P. Soubrier, Congress I.A.S.P. 1981, 25 rue de la Faisanderie, 75116 Paris, France.

A one-day MIND conference on 'Crisis Intervention Services' will be held on 12 May 1981 at Thomas Coram Centre, London WC 1. Information: Conference Secretary, 22 Harley Street, London WIN 2ED. 